\title{
Infestation of extraocular muscle by Cysticercus cellulosae
}

\author{
David A DiLoreto, Ross A Kennedy, Janet M Neigel, Jack Rootman
}

\begin{abstract}
Reports of orbital cysticercosis are uncommon despite the high incidence of brain and ocular involvement. Infestation of extraocular muscle is exceedingly rare. Two cases of cysticercosis of the extraocular muscles are reported here. Surgical removal of the encysted parasites successfully resolved the infestation in both cases.
\end{abstract}

While intraocular infections by Cysticercus cellulosae are often found as part of a generalised systemic infestation, ocular adnexal involvement is rare. We report two cases of cysticercosis of an extraocular muscle. The presenting features mimicked subacute orbital myositis in one patient and an orbital tumour in the second.

\section{Case reports}

\section{CASE I}

A 35-year-old Cambodian woman was referred to

Department of

Ophthalmology,

University of British

Columbia, Vancouver,

BC, Canad

D A DiLoreto

R A Kennedy

$\mathrm{J} M$ Neigel

J Rootman

Correspondence to: David DiLoreto, $M D$

LSU Eye Center,

LSU Eye Center,

2020 Gravier Street,

Louisiana 701122234 , USA

Accepted for publication

4 December 1989 the Orbital Clinic at the University of British Columbia with complaints of right orbital pain and swelling associated with diplopia in lateral gaze. Treatment with topical and systemic antibiotics was ineffective, and the pain had progressed. The visual acuity on both sides was $6 / 6$. There was $4 \mathrm{~mm}$ of right proptosis. The right eye movements were limited in abduction and adduction by severe pain. The conjunctiva over the right lateral rectus muscle was injected with inferolateral chemosis. Anterior segment and ocular fundus examination gave normal results. A general physical examination and

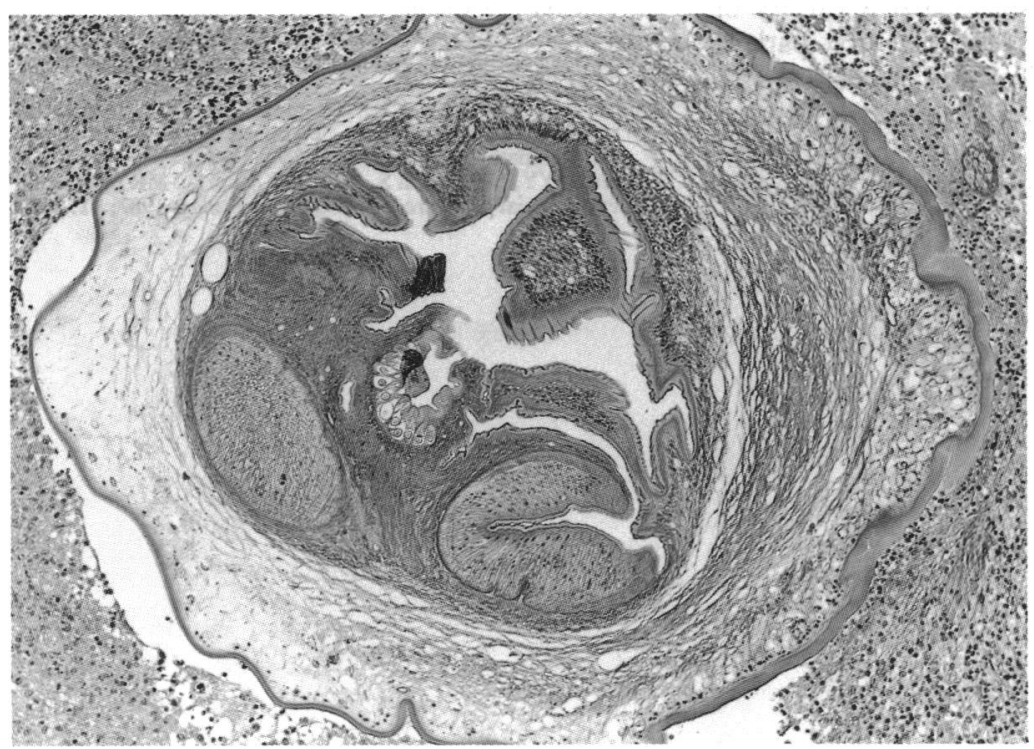

Figure 2: Note scolex with suckers and folding of tegmentum $(\times 7$.)

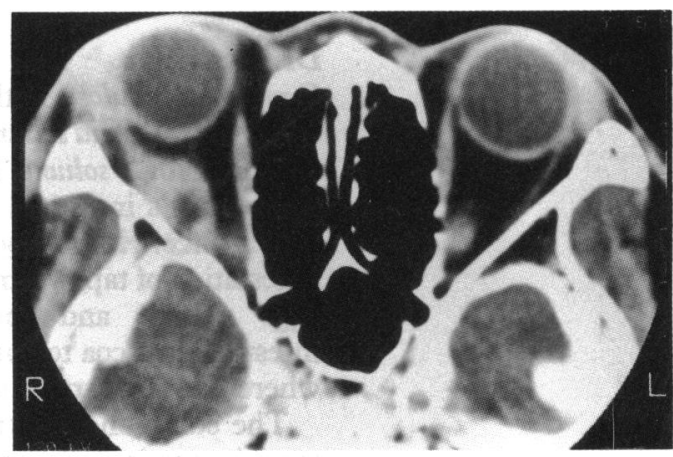

Figure 1: Computed axial tomogram of case one. Orbital mass contiguous with right lateral rectus muscle. Note central lucency.

complete blood count showed normal results, and there was no eosinophilia. B-scan ultrasonogaphy demonstrated a mass within the lateral rectus muscle. Orbital computed tomography revealed a retrobulbar mass with a central lucency involving the right lateral rectus muscle (Fig 1). The differential diagnosis included orbital abscess and tumour. A transconjunctival orbital biopsy was performed laterally. A firm fibrotic mass within an enlarged muscle belly was encountered and removed. Histopathological examination showed a cystic structure lined by a thick fibrous wall containing the parasite Cysticercus cellulosae (Fig 2).

\section{CASE 2}

A 7-year-old girl of East Indian origin was seen with complaints of a painless, progressively enlarging epibulbar mass (Fig 3). She had lived in North America her entire life except for a vacation in India one year prior to presentation. Her past medical history was unremarkable, and her visual acuity was $6 / 6$ in both eyes. A $1 \mathrm{~cm}$ soft solid mass was present subconjunctively over the left medical rectus muscle. The left globe was displaced laterally without proptosis. Examination of the anterior segment and ocular fundus gave normal results, as did a general

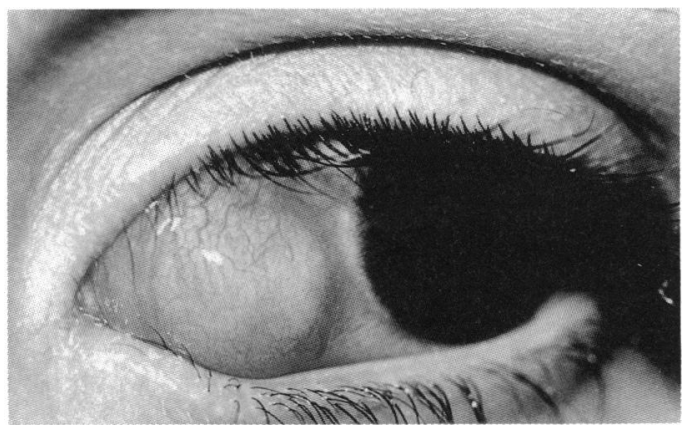

Figure 3: Case 2. Anterior orbital mass overlying left medial rectus muscle. 
physical examination. A complete blood count was normal, with no eosinophilia. A CT scan of the orbits showed an enhancing mass of the left medial orbit involving the medial rectus muscle. Because of the possibility of an orbital tumour a transconjunctival exisional biopsy was performed. Histopathological studies of the excised mass revealed a cyst containing a cysticercus surrounded by granulation tissue.

\section{Discussion}

Cysticercus cellulosae is the larval form of the pork tapeworm, Taenia solium. Man is the only known final host for $T$ solium. The organism can remain in the host's intestinal tract causing little or no disturbance. Human cysticercosis is acquired by ingestation of tapeworm eggs shed in faeces. The eggs mature and the larvae penetrate the intestinal muscoa to enter the portal circulation, where they are carried to other organs.'

The commonest pattern of systemic involvement is seen in neurocysticercosis and appears as a space occupying intracranial lesion. Treatment is with praziquantel ${ }^{2}$ and surgical excision of cysts unresponsive to medical therapy or for relief of intracranial hypertension. ${ }^{3}$

The larval forms may enter the eye through the choroidal circulation and migrate in the subretinal space or enter the vitreous. ${ }^{4}$ Death of the larvae within ocular tissues can stimulate severe inflammatory reaction. Such infestations are an important cause of blindness in the endemic areas of South-east Asia, Central America, and Africa. Medical therapy has not proved successful, and treatment is surgical excision. ${ }^{46}$

Ocular adnexal infestation in cysticercosis is unusual. Six cases of eyelid involvement have been reported..$^{711}$ Sen $^{10}$ studied four additional cases with orbital involvement. Case reports of infestation of extraocular muscle are exceptional..$^{12}$ The classical description of orbital cysticercosis is that of an anterior orbital mass with a severe inflammatory reaction. ${ }^{14}$ The patients may experience considerable pain accompanied by oedema, chemosis, ptosis, optic neuritis, and restriction of extraocular movements.

Our two cases demonstrate that a variety of clinical features may be seen. The first patient presented with signs of orbital myositis with moderate proptosis due to the posterior location of the cyst. Our second patient lacked inflammatory features and presented with a painless anterior orbital mass.
The diagnosis of cysticercosis can be presumptively established by the presence of small calcific densities on roentgenogram of the skull or extremities. Other tests such as electroencephalography, CT scan, or arteriography may confirm space occupying intraparenchymal brain lesions. Eosinophilia may be present in disseminated disease. Serological testing is often inconclusive, more than $50 \%$ of patients with neurocysticercosis having no quantifiable antibody response. ${ }^{\text {is }}$ Spinal fluid analysis with radioimmunoassay may reveal detectable titres. The diagnosis of non-calcified orbital cysticercosis may be elusive until the cyst is surgically excised. Removal typically results in complete resolution of symptoms, as was the case for both our patients.

Magnetic resonance imaging of neurocysticercosis is well documented..$^{16}$ In a recent case of orbital cysticercosis it produced images of cysts in extraocular muscle and outlined a scolex within a cyst. ${ }^{17}$ Although additional confirmation is necessary, MR imaging may be the best method of assessing patients with presumed orbital cysticercosis.

1 Dalton HP, Nottebart HC. Interpretive medical microbiology New York: Churchill Livingstone, 1986: 291.

2 Moodley M, Moosa A. Treatment of neurocysticercosis: is praziquantel the new hope? Lancet 1989; i: 262-3.

3 Robles C, Sedano AM, Vargas-Tentori N, Galdino-Virgen S. Long-term results of praziquantel therapy in neurocysticercosis. F Neurosurg 1987; 66: 359-63.

4 Maschot WA. Intraocular cysticercosis. Arch Ophthalmo 1968; 80: 772-4.

5 Messner KH, Kammerer WS. Intraocular cysticercosis. Arch Ophthalmol 1979; 97: 1103-5.

6 Kestilyn P, Taelman H. Effect of praziquantel on intraocular cysticercosis: a case report. $\operatorname{Br} \mathcal{F}$ Ophthalmol 1985; 69: 78890.

7 Jampol LM, Caldwell JBH, Albert DM. Cysticercus cellulosae in the eyelid. Arch Ophthalmol 1973; 89: 319-20.

8 Malik SRK, Gupta AK, Choundry S. Ocular cysticercosis. Am f Ophthalmol 1968; 66: 1168-71.

FOphthalmol 1968; 66: 1168-71.
Perry HD, Font RL. Cysticercosis of the eyelid. Arch Ophthal mol 1978; 96: 1255-7.

10 Sen DK. Cysticercus cellulosae in the eyelid, orbit and lacrimal gland. Acta Ophthalmol (Kbh) 1980; 58: 144-7.

11 Sing G, Kaur J. Cysticercosis of the eyelid. Ann Ophthalmol $1982 ; 14: 947-50$

12 Brooks AM, Essex WB, West RH. Cysticercosis of superior oblique muscle. Aust $\mathscr{f}$ Ophthalmol 1983; 11: 119-22.

13 Rao VA, Kawatra VK, Ratnakar C. Unusual cause of acquired inflammatory Brown's syndrome. Can $\mathcal{F}$ Ophthalmol 1987; 22: $320-2$.

14 Duke-Elder S. System of ophthalmology London: Kimpton 1974; 13: (2): 929-30.

15 Flisser A, Woodhouse E, Larralde C. Human cysticercosis: antigens, antibodies and non-responders. Clin Exp Immunol antigens, antibodics

16 Suss RA, Maravilla KR, Thompson J. MR imaging of intracranial cysticercosis: comparison with $\mathrm{CT}$ and intracranial cysticercosis: comparison with CT

17 Cheung YY, Steinbaum S, Yuh WT, Chiu L. MR findings in extracranial cysticercosis. $\mathcal{F}$ Comput Tomogr 1987; 11: 17981. 